\title{
Personality and Young Adult Financial Distress
}

\begin{abstract}
Researchers have become increasingly interested in understanding the sources of heterogeneity in individual financial behaviors. In this paper, we examine how the Big Five personality traits are related to measures of young adults' financial distress. Using data from the National Longitudinal Study of Adolescent to Adult Health in the United States, we find that conscientiousness is negatively correlated, and neuroticism positively correlated with financial distress. These correlations are robust to controlling for early life background and other demographic and socioeconomic factors. Young adulthood sets the stage for financial security in later life; as such, this study provides insight for lifelong financial wellbeing. Based on the empirical results, we discuss potential behavioral or policy interventions that can be used to improve financial wellbeing.
\end{abstract}

Keywords: personality traits, conscientiousness, neuroticism, financial distress 


\section{Introduction}

Social scientists have long been interested in the determinants of financial well-being of individuals. In nearly any study of financial behavior or outcomes, from retirement planning to wealth accumulation, there is substantial cross-sectional variation that is not explained by standard demographic or economic variables. Although social scientists may never be able to decompose individual fixed effects fully into all their constituent parts, it is important to better understand the source of individual variation in financial behavior and outcomes so that we can better determine the extent to which they can be altered by behavioral or policy interventions to improve financial well-being.

In this paper, we explore how personality traits, which are defined as the relatively enduring patterns of thoughts, feelings, and behaviors that develop with time and age and are elicited in trait-relevant situations (Roberts, 2009), explain individual differences in financial distress in young adulthood. Young adulthood is a time when many important financial decisions are being made for the first time. The financial behaviors and psychological traits established in young adulthood have general implications because they extend throughout adulthood into later life and set the stage for lifelong financial outcomes (Eccles, Ward, Goldsmith, and Arsal, 2013). Specifically, we examine indicators of financial distress such as missing utility bills, losing phone service, missing mortgage or rent payments, being insolvent, worrying about food depletion, and using public assistance. We also aggregate these indicators into a composite measure of financial distress. All these types of financial distress can occur based on inadequate income as well as weak cash-flow management behavior (Eccles et al., 2013). Successful financial management requires one to formulate and implement a financial plan (Yao and $\mathrm{Xu}$, 2014), resist temptation (Gathergood, 2012; Gul and Pesendorfer, 2004; Thaler and Shefrin, 1981), and deal with social comparison (K. M. Brown and Laschever, 2012; Bursztyn, Ederer, 
Ferman, and Yuchtman, 2012). Financial management is often manifest as specific behaviors, such as paying bills on time, saving money for future inevitabilities such as emergencies and retirement, and avoiding too much debt (S. Brown and Taylor, 2014).

Our research builds on previous literature in psychology and economics documenting the predictive power of personality traits on major socioeconomic outcomes including earnings, wealth accumulation, schooling, occupational attainment, mortality and divorce (Bowles, Gintis, and Osborne, 2001b; Duckworth, Weir, Tsukayama, and Kwok, 2012; Heckman, Stixrud, and Urzua, 2006; Letkiewicz and Fox, 2014; Lundberg, 2013; Roberts, Kuncel, Shiner, Caspi, and Goldberg, 2007). Our study is one of the first to extend this line of research to the relation of personality traits to behavioral inputs to economic well being in the form of indicators of financial distress in young adulthood.

The standard economic predictors of financial outcomes typically include factors such as socioeconomic background, education, and cognitive ability. In moving beyond these standard predictors, there are a multitude of options including broad and narrow personality traits, motivations, and life narratives (D. P. McAdams and Pals, 2006; Roberts, 2006). We chose to focus on personality traits, and in particular the Big Five, as predictors of financial behavior for three reasons. First, financial management behaviors to the extent that they reflect broader themes of planfulness, impulse control, and persistence, are clearly linked at a conceptual level to personality traits such as conscientiousness (Roberts, Lejuez, Krueger, Richards, and Hill, 2014).

Second, we chose to focus on personality traits because unlike other potential domains, much work has gone into organizing and structuring trait domains into a more generalizable taxonomy. The ideal organizing structure for personality traits is still a matter of 
debate with some proposing five factors (John, Naumann, and Soto, 2008) and others a six-factor solution (Ashton and Lee, 2007). Nonetheless, the Big Five have been used widely in both concurrent and longitudinal studies (e.g., Fletcher, 2013b; Hill, Turiano, Mroczek, and Roberts, 2012; Roberts, Jackson, Duckworth, and Culin, 2011) and provides an excellent starting point for the investigation of factors beyond the standard economic predictors that might predict financial distress. The Big Five includes conscientiousness, emotional stability/neuroticism, extraversion, agreeableness, and openness to experience. Conscientiousness reflects the tendency to work hard, control one's impulses, be organized, and follow through with obligations (Roberts et al., 2014). Neuroticism refers to the tendency to experience excess worry, depression, anger and distress (John et al., 2008). Extraversion is "an orientation of one's interests and energies toward the outer world of people and things rather than the inner world of subjective experience, characterized by positive affect and sociability" (VandenBos, 2007); agreeableness represents "the tendency to act in a cooperative, unselfish manner" (VandenBos, 2007). Finally, openness to experience represents "the tendency to be open to new aesthetic, cultural, or intellectual experiences” (VandenBos, 2007).

A third reason to focus on personality traits is their breadth and generality. While narrow traits can often be used to maximize prediction of outcomes, they sometimes come with a cost. For example, confidence in one's ability to perform well in mathematics predicts mathematics performance quite well, but not outcomes from other, more disparate domains (Trautwein, Lüdtke, Roberts, Schnyder, and Niggli, 2009). In contrast, a trait such as conscientiousness, because of its generality, not only predicts mathematics performance, but also performance in other domains such as in language arts (Trautwein et al., 2009). Personality traits are also generalizable across the life course, such that they exist even in the absence of the outcome of 
interest, such as in the present study, which is financial distress. For example, it would be difficult to measure financial planning in young children as they are seldom afforded the opportunity to handle and manage money. On the other hand, the Big Five personality traits have been measured and identified across the life course and can therefore be used before the outcomes of interest, such as financial difficulties have even been considered (e.g., Moffitt et al., 2011) Another advantage of the generality of the Big Five personality traits is that they have been widely used and are therefore a common scientific vernacular for not only understanding the processes of human functioning, but also for organizing disparate scientific findings and literatures (Roberts et al., 2011).

Although the examination of the association of the Big Five to a wide range of financial outcome measures in a representative sample is uncommon, each of the Big Five has been linked to broad financial outcomes that are related to the outcomes considered here. For example, all of the Big Five have been shown to predict salary (Roberts et al., 2011). In a meta-analysis of prospective longitudinal studies, conscientiousness, extraversion, and openness predicted higher salaries and both neuroticism and agreeableness lower salaries (see also, Heineck, 2011). A similar pattern of associations was found in the Household, Income and Labor Dynamics in Australia (HILDA) sample when predicting household income (Boyce, Wood, and Powdthavee, 2013). Moreover, conscientiousness was also associated with higher levels of wealth accumulation in the Health and Retirement Study (Duckworth et al., 2012). Conversely, several of the Big Five show prospective associations to patterns of unemployment. Conscientiousness was associated with finding a job faster after becoming unemployed and in experiencing a shorter duration of unemployment, whereas neuroticism predicted the opposite (Uysal and Pohlmeier, 2011). Openness appeared to have a more complex relation to unemployment, with 
one study showing a shorter duration for those willing to move (Uysal and Pohlmeier, 2011) and a second study showing higher cumulative rates of unemployment for those who were more open to experience, possibly because of the types of jobs they pursued, such as artistic careers, which are less stable (Viinikainen and Kokko, 2012).

In terms of outcomes more closely associated with those considered in this study, which focuses primarily on ones indicative of financial distress, there are few related studies. In a longitudinal prospective study of Iowans, adolescent conscientiousness predicted lower rates of economic pressure in young adulthood (Donnellan, Conger, McAdams, and Neppl, 2009). Unfortunately, this study did not report associations between personality and financial distress for the remaining Big Five. Moreover, their single composite measure of economic pressure used "household indices of economic hardship" for 438 participants, a sample that is small and not nationally representative. Just recently, the association between the Big Five and both unsecured debt and financial assets was examined in the British Household Panel Study (S. Brown and Taylor, 2014). Consistent with past research on debt (Nyhus and Webley, 2001), conscientious individuals had lower rates of debt. In contrast, those reporting higher extraversion and agreeableness had higher debt loads and extraverted individuals, fewer assets. But, the study found no significant relations with neuroticism. Similarly, individuals from the Health and Retirement study who were more likely to need financial assistance also scored higher in neuroticism and agreeableness (Gillen and Kim, 2013).

Each of the Big Five domains has been linked to certain financial outcomes in prior research. The most consistent pattern across outcomes emerges for conscientiousness, which appears to be uniformly associated with positive financial standing. While less consistent, the findings for neuroticism appear to be clear and linked to negative financial status. Based on 
these patterns, we hypothesize that conscientiousness will be negatively and neuroticism positively associated with measures of financial distress. Conversely, the most salient pattern for agreeableness was negative, such that it was associated with lower earnings. Therefore, we would hypothesize that higher levels of agreeableness would be associated with higher levels of financial distress. Both extraversion and openness to experience demonstrate more complex associations with financial outcomes, with some studies showing positive effects, and some negative effects. Therefore, we make no directional hypotheses for these two trait domains.

We test our hypotheses using a nationally representative sample of young adults in the United States surveyed by the National Longitudinal Study of Adolescent to Adult Health (Add Health). We find that conscientiousness is negatively correlated and neuroticism positively correlated with all six individual measures and one composite measure of financial distress. The remaining Big Five - extraversion, agreeableness, and openness to experience - are only correlated with selected measures of financial distress. The results for conscientiousness and neuroticism are robust to the inclusion of a rich set of controls for early life background and demographic and socioeconomic factors that may be associated with financial distress. Moreover, adding controls for household income in young adulthood does not attenuate the effects of conscientiousness and neuroticism, suggesting that these two personality traits explain individual differences in unobservable behavioral patterns that lead to financial distress independently of differences in income. For example, personality may affect one's time preference, sense of efficacy, and sense of shame (Bowles, Gintis, and Osborne, 2001a; 2001b; Roberts et al., 2007). The findings have implications for lifelong financial wellbeing because young adulthood sets the stage for wealth accumulation and financial success. Personality-based 
policy interventions have the potential to improve financial wellbeing, as we will discuss in the conclusion.

\section{Empirical Method}

The dataset we use is the National Longitudinal Study of Adolescent to Adult Health (the Add Health), which broadly studies health, health behaviors and their contexts for a nationally representative sample of adolescents in the United States. Wave I, conducted in 1994-1995, consisted of approximately 90,000 adolescents in grades $7-12$ from a stratified sample of 143 high schools and their “feeder schools.” Waves II (1995/1996), III (2001/2002), and IV (2007/2008) surveys followed a subsample of approximately 15,000 into their young adulthood (ages 24-34). The independent variables of interest, the Big Five personality traits, were assessed only in Wave IV. In addition to the demographic and socioeconomic environments in adolescence and young adulthood, we are also able to control for individual and family background at Wave I, capturing a comprehensive set of early life experiences that could potentially affect financial outcomes in young adulthood (Wave IV). This methodological approach follows that taken in earlier research on different outcomes using the Add Health data (Slade and Beller, 2013).

We restrict the sample to respondents with no missing values for the dependent, independent, and control variables. We exclude adolescents whose age is outside of the normal range for $7^{\text {th }}-12^{\text {th }}$ graders, i.e., those younger than 13 (4.26\% of the Add Health Wave I sample) and older than 18 (3.88\% of the Add Health Wave I sample). The sample is reduced to 13,470 after all sample restrictions. We use the Wave IV cross-sectional sampling weights in our estimation to correct for the complex survey design that oversamples certain subpopulations. 
The average age of the sample as of the Wave IV survey was 28.4; 49.5 percent were female, and 50.5 percent had ever been married by the time of Wave IV survey. Broken down by race and ethnic origin, 65.8 percent were white, 15.9 percent Black, 11.8 percent Hispanic, 3.5 percent Asian, and 3.0 percent other race. Additional summary statistics about the demographic, socioeconomic status and early life background factors of the young adults in the sample are reported in Table 1.

\section{Empirical Strategy}

In this paper, we estimate the relations between a given category of financial distress and personality traits using a Probit model:

$\operatorname{Prob}\left(F_{i}=1\right)=\alpha+\beta P_{i}+\gamma X_{i}+\epsilon_{i}$.

The dependent variable, $F_{i}$, is an indicator that equals one if a young adult respondent $i$ reports that they experience a category of financial distress (discussed below). The independent variable $P_{i}$ is a vector of the Big Five personality traits at young adulthood, namely, conscientiousness, neuroticism, extraversion, agreeableness, and openness to experience. We normalized the personality measures so that the marginal effects estimated from the Probit model can be interpreted as the marginal effects of one-standard deviation change in the personality scales on the probability of experiencing a particular kind of financial distress. The control variables $X_{i}$ is a vector of demographic, socioeconomic, and early life background factors observed in either adolescence or young adulthood. The error term is denoted by $\epsilon_{i}$. We also estimate two augmented models. In the first, we add a vector of variables for early life background including childhood family structure, health, mathematical abilities, and parental 
education. In the second model, we further control for the young adult's household income in Wave IV.

We first construct six binary measures of financial distress based on the respondents' answers to the following questions, with a value of one indicating a positive answer to the question and a value of zero otherwise:

(1) "In the past 12 months, was there a time when \{YOU/YOUR HOUSEHOLD\} didn't pay the full amount of a gas, electricity, or oil bill because you didn't have enough money?”

(2) "In the past 12 months, was there a time when \{YOU/YOUR HOUSEHOLD\} was without phone service because you didn't have enough money?”

(3) "In the past 12 months, was there a time when \{YOU/YOUR HOUSEHOLD\} didn't pay the full amount of the rent or mortgage because you didn't have enough money?”

(4) "Suppose you and others in your household were to sell all of your major possessions (including your home), turn all of your investments and other assets into cash, and pay off all of your debts. Would you have something left over, break even, or be in debt?”

(5) "In the past 12 months, was there a time when \{YOU/YOUR HOUSEHOLD WERE/WAS \} worried whether food would run out before you would get money to buy more?”

(6) "Between $\{1995 / 2002\}$ and $\{2006 / 2007 / 2008\}$, did you or others in your household receive any public assistance, welfare payments, or food stamps?”

Although questions 1-3 and 5 are related to income, these measures also reflect poor financial management, particularly after controlling for household income in an augmented model. We 
further create a composite measure of financial distress by adding all six binary variables together. We estimate its correlations with the Big Five personality traits using an OLS model.

As presented in Table 1, in the 12 months preceding the Wave IV survey, 15.0 percent of the young adults in our sample missed a utility bill, 8.8 percent went without phone service, and 9.6 percent missed a mortgage/rent payment. About 19.4 percent of the respondents were insolvent, 11.5 percent worried about depleting their food, and 24.4 percent had received public assistance of some type since their previous interview. The composite measure of financial distress had an average value of 0.886 for this sample, meaning the average young adult had experienced one out of the six measures of distress. The relatively high rate of insolvency in part reflects that some of the homeowners (about 40 percent of our sample) could be underwater with their mortgages during the onset of the U.S. Great Recession, and the potential impact of unpaid student loans.

The main independent variables of interest are the Big Five personality traits. The Add Health Wave IV utilized a 20-item short-form version of the International Personality Item PoolFive-Factor Model (i.e., the Mini-IPIP) (Donnellan, Oswald, Baird, and Lucas, 2006). Each measure of those personality inventories was constructed from four questions. The young adult respondents rated how much they agreed with each statement about themselves using a five-level Likert scale ranging from "strongly agree" (1 point) to "strongly disagree" (5 points). For example, the items used to assess conscientiousness include "I get chores done right away." (Reverse coded, "strongly disagree" (5 points) means low conscientiousness.) "I often forget to put things back in their proper place." "I like order.” (Reverse coded.) "I make a mess of things.” The items for neuroticism include "I have frequent mood swings." (Reverse coded.) "I am relaxed most of the time." "I get upset easily." (Reverse coded.) "I seldom feel blue.” The 
constructed measures range from 4 to 20, with the higher scores representing higher levels of the personality traits. The average personality trait scale is around 14, except for neuroticism, which averages around 10 (see Table 1 for detailed summary statistics).

In the baseline model, we control for demographic and socioeconomic variables such as gender, race/ethnic origin, age, and marital status, employment prospects measured by geographic region and the unemployment rate of persons 16 years and over at the census tract

level, and educational attainment. In the first augmented model, we also control for early life background factors including family structure, health, and mathematical abilities in adolescence and parental education, which could contribute to differences in young adult financial outcomes. Family structure is assessed by the presence or absence of the biological father from the household and whether a stepfather or cohabiting partner of the mother is there (Slade and Beller, 2013). Health includes measures of self-reported health and of depression in Wave I (Slade and Beller, 2013), and of an ADHD diagnosis at any time up to Wave IV (Aizer, 2008; Fletcher, 2013a). Mathematical ability is measured by the adolescent's grade on their last math test (Agarwal and Mazumder, 2013). In the second augmented model, we also control for the young adult's household income measured according to the approximate quintiles provided in the Add Health. (See summary statistics in Table 1).

\section{Empirical Results}

\section{Personality Traits and Young Adult Financial Distress}

Table 2 presents the marginal effects from the baseline model where, along with personality, we only control for demographics. We adjusted the estimation results by Wave IV cross-sectional sampling weights to reflect the marginal effects for representative young adults. 
As hypothesized, conscientiousness is negatively related to all six measures of financial distress. A one-standard deviation increase in conscientiousness reduces the likelihood of missing utility bills by 3.8 percent, losing phone service by 1.8 percent, missing rent or mortgage payments by 1.9 percent, being insolvent by 2.8 percent, facing no food by 2.5 percent, and being on welfare by 1.9 percent. It also lowers the aggregate indicator of financial distress by 0.157 , the equivalent of 17.7 percent of the sample mean of 0.886 . All these estimates are significant at $p<.01$. The first panel of Figure 1 plots the confidence intervals of the marginal effects of conscientiousness on each of the financial distress measures. The estimation results suggest that conscientious young adults handled their household finances better than average in all dimensions that we consider.

Also as hypothesized, neuroticism works the opposite of conscientiousness - a onestandard deviation increase in neuroticism raises the likelihood of missing utility bills by 2.8 percent, losing phone service by 2.2 percent, missing a mortgage/rent payment by 2.0 percent, being insolvent by 1.9 percent, worrying about no food by 3.5 percent, and being on public assistance by 2.7 percent, and the financial distress indicator by an equivalent of 18.4 percent (marginal effect 0.163 over sample mean of 0.886 ). The estimates are significant at $\mathrm{p}<.01$. The first panel of Figure 2 plots the confidence intervals of the marginal effects. The absolute values of these marginal effects are roughly the same as for conscientiousness, suggesting that neurotic individuals have a somewhat more difficult time handling their finances, in a manner that can counteract the beneficial effect of conscientiousness.

The patterns for the remaining personality traits are less consistent. To the extent that we find statistically significant results, extraversion is related to a lower likelihood of financial distress, agreeableness and openness to a higher likelihood. For instance, a one-standard 
deviation increase in extraversion reduces the likelihood of being insolvent by 1.3 percent, on welfare by 1.5 percent, and the composite financial distress indicator by 0.032 . A one-standard deviation increase in agreeableness is associated with a 0.9 percent increase in the likelihood of missing utility bills and 1.0 percent increase in worrying about food depletion. A similar increase in the openness measure is associated with an increase in the likelihood of missing utility bills by 1.5 percent, missing mortgage/rent payment by 0.8 percent, becoming insolvent by 2.1 percent, and a 0.051 increase in the composite financial distress indicator.

\section{Robustness to Early Life Background}

Next we examine the relations between personality traits and financial distress by further controlling for the effect of early life background. We control for family structure, health, and mathematical abilities in adolescence and parental education, all of which could potentially be correlated with young adult financial outcomes and personality development. Table 3 reports the marginal effects. Despite the relative importance of the background measures, the negative relations between conscientiousness and all seven indicators of financial distress are still statistically significant, and the magnitudes of the marginal effects are similar to those in the baseline case. The positive marginal effects of neuroticism are also statistically significant and only slightly smaller in magnitudes than those in the baseline case. A visual comparison of the marginal effects to those in the baseline case can be seen in the first two panels of Figures 1 and 2 for conscientiousness and neuroticism, respectively. The confidence intervals of the marginal effects in the upper left panel (baseline case) largely overlap the confidence intervals in upper right panel (controlling for early life background) for each category of financial distress. The similar marginal effects imply that conscientiousness and neuroticism are two important 
personality factors that help explain differences in financial distress unexplained by differences in early life backgrounds.

\section{Financial Mismanagement or Poverty?}

The indicators of financial distress we have examined could result from not having enough money, skill deficits in day-to-day financial management, or both. It remains unclear whether the estimates of personality traits are picking up the former, which can be related to certain personality traits. To address this concern, we further control for current annual household income in young adulthood. We control for household income rather than personal income to minimize the direct correlation between income and other individual characteristics. If the adverse financial outcomes were simply due to insufficient income as opposed to mismanagement of household finance, the personality traits would have little or no impact on these financial outcomes once household income was controlled for. However, if the estimates remain significant after controlling for income, it would bolster our confidence that such adverse outcomes were the result of financial mismanagement that can be explained by individual differences in certain personality traits.

Table 4 reports the results for the association of personality traits with indicators of financial distress when controlling for household income in addition to demographics and early life background. Adding household income further attenuates but does not fully absorb the marginal effects of conscientiousness and neuroticism, suggesting that individual differences in the two traits are associated with differences in financial outcomes independently of the effect through household income. The confidence intervals of the marginal effects are plotted in the third panels of Figures 1 and 2 for conscientiousness and neuroticism, respectively. A few 
marginal effects become less precisely measured - the marginal effects of conscientiousness and neuroticism on welfare are statistically significant only at the 5 percent level, and the marginal effect of neuroticism on insolvency at the 10 percent level. Compared to the confidence intervals in the baseline case (the first panel) and the first augmented model where we control for early life background in addition to demographics (the second panel), the marginal effects become slightly smaller after controlling young adult household income but still statistically significantly away from zero. This suggests that personality traits are likely to explain the unobservable individual differences in behavioral patterns that lead to adverse financial outcomes independent of the effect of household income.

\section{Conclusion}

In this paper, we introduce the Big Five personality traits as an important factor that explains a set of indicators of financial distress. Specifically, we find that more conscientious young adults are less likely to experience financial distress, while more neurotic ones are more likely. These patterns persist across all seven financial indicators we examined. The patterns with the remaining personality traits were less consistent across measures of financial distress. However, to the extent there were significant effects, more extraverted young adults were less likely to experience financial distress, while the ones who were more agreeable or more open to experience were more likely to go through financial distress.

We found that the relations between personality traits and financial distress were robust to the inclusion of early life background factors such as family structure, health, and education, and other demographic and socioeconomic factors. This suggests that personality traits are human capital factors that are independent of other background factors that contribute to young 
adults' financial outcomes. Despite the fact that the literature suggests that conscientiousness and neuroticism explain differences in wages and wealth, we found that these personality traits remained as strong predictors of adverse financial outcomes even after controlling for annual household income in young adulthood. This suggests that personality traits are associated with financial distress through channels other than solely limited financial resources. We argue that conscientiousness and neuroticism are likely to be related to the psychological barriers and behavioral patterns that hinder sound management of finances.

A better understanding of what leads to poor financial outcomes can suggest alternative interventions to promote financial well-being in the next generation. The associations between personality traits and financial distress suggest the possibility of designing behavioral interventions based on personality traits, in a way similar to customized medication where medication and treatment are given based on the patient's genetic make-up. To the extent that personality traits are associated with behavioral patterns that hinder financial wellbeing, these personality traits can be used to identify the population at financial risk. Financial products can be designed to overcome the negative effects of certain personality traits. For example, one could imagine financial planning tools that help make consumers aware of their lack of conscientiousness and self-control and then provide behavioral interventions to help them overcome them. Alternatively, interventions to help with financial planning could be focused on individuals identified as low on conscientiousness and high on neuroticism so as to alleviate the potential negative effects of these dispositions.

Moreover, recent research suggests such traits are malleable and can be modified in childhood as well as later in life (Jackson, Hill, Payne, Roberts, and Stine-Morrow, 2012). Interventions with non-cognitive skills of young children may be aimed at increasing 
conscientiousness and, to the extent possible, reducing neuroticism. Neuroticism is a trait that can be intervened with psychological therapies. Uncertainty and fear are at the core of neuroticism. Children can be made to feel safe and secure so they can explore new things. To the extent that they get the opportunity to master new skills, they will have fewer fears going forward. Research has shown that even children as young as preschool age can undergo an intervention to alleviate anxiety disorders (Rapee, Kennedy, Ingram, Edwards, and Sweeney, 2005). In general, early interventions to develop non-cognitive abilities can have long lasting effects: for example, researches have shown how pre-school interventions that focus on enhancing non-cognitive skills can increase earnings later in life (Heckman, Moon, Pinto, Savelyev, and Yavitz, 2010; Heckman, Savelyev, and Pinto, 2013).

Our findings contribute to public policies aimed at improving the welfare of senior citizens. One's preparedness for retirement is, to a large extent, pre-determined by the range of financial decisions made earlier in life. The consequences of financial mis-management can be more detrimental in later life as income decreases and medical expenses increase. Of the several important rationales for why a mandatory public system like Social Security may be an optimal feature of the U.S. retirement landscape is the notion that some segments of the population will lack the skills and knowledge needed to adequately prepare for retirement on their own. In the private sector, the rapidly growing literature on the use of default options is also predicated on the notion that many individuals will not behave optimally in the absence of "nudges." Our research suggests several ways to better target behavioral nudges to be most effective for subpopulations that differ along personality-based dimensions.

Our study is limited to correlations between personality and indicators of financial distress, and does not establish causal relations. Although the significant relations for 
conscientiousness and neuroticism with indicators of financial distress are supportive of our hypotheses, we recognize that experiencing financial distress could affect the degree to which one is conscientious or neurotic, especially if these traits are malleable. Future research should attempt to overcome such concerns about reverse causality in order to identify a causal connection.

\section{Acknowledgements}

This research was supported by National Institute of Food and Agriculture, the U.S. Department of Agriculture (under award number \#ILLU-470-367) and the U.S. Social Security Administration (SSA) through grant \#RRC08098400-07 to the National Bureau of Economic Research (NBER) as part of the SSA Retirement Research Consortium. The findings and conclusions expressed are solely those of the authors and do not represent the views of the U.S. Department of Agriculture, the SSA, any agency of the Federal Government, or the NBER. This paper has benefitted from a poster presentation at the American Economic Association meetings, Philadelphia, Pa., January 2014, and from a paper presentation at the Association for Public Policy Analysis and Management Conference on "The Decline of the Middle Classes Around the World?”, Segovia, Spain, September 2014. The authors thank Shanshan Wang for excellent

research assistance, and Genevieve Melford and Melissa Knoll of the CFPB for useful discussions. This research uses data from Add Health, a program project directed by Kathleen Mullan Harris and designed by J. Richard Udry, Peter S. Bearman, and Kathleen Mullan Harris at the University of North Carolina at Chapel Hill, and funded by grant P01-HD31921 from the Eunice Kennedy Shriver National Institute of Child Health and Human Development, with cooperative funding from 23 other federal agencies and foundations. Special acknowledgment is 
due Ronald R. Rindfuss and Barbara Entwisle for assistance in the original design. Information on how to obtain the Add Health data files is available on the Add Health website (http://www.cpc.unc.edu/addhealth). No direct support was received from grant P01-HD31921 for this analysis. 


\section{References}

Agarwal, S., and Mazumder, B. (2013). Cognitive abilities and household financial decision making. American Economic Journal: Applied Economics, 5(1), 193-207.

Aizer, A. (2008). Peer effects and human capital accumulation: The externalities of ADD (No. w14354). National Bureau of Economic Research.

Ashton, M. C., and Lee, K. (2007). Empirical, theoretical, and practical advantages of the HEXACO model of personality structure. Personality and Social Psychology Review. 11(2), 150-166

Bowles, S., Gintis, H., and Osborne, M. (2001a). Incentive-Enhancing Preferences: Personality, Behavior, and Earnings. American Economic Review, 91(2), 155-158.

Bowles, S., Gintis, H., and Osborne, M. (2001b). The Determinants of Earnings: A Behavioral Approach. Journal of Economic Literature, 39(4), 1137-1176.

Boyce, C. J., Wood, A. M., and Powdthavee, N. (2013). Is Personality Fixed? Personality Changes as Much as “Variable” Economic Factors and More Strongly Predicts Changes to Life Satisfaction. Social Indicators Research, 111(1), 287-305. doi:10.1007/s11205-012-0006-z

Brown, K. M., and Laschever, R. A. (2012). When They're Sixty-Four: Peer Effects and the Timing of Retirement. American Economic Journal: Applied Economics, 4(3), 90-115. doi:10.1257/app.4.3.90

Brown, S., and Taylor, K. (2014). Household finances and the "Big Five” personality traits. Journal of Economic Psychology, 45, 197-212. doi:10.1016/j.joep.2014.10.006

Bursztyn, L., Ederer, F., Ferman, B., and Yuchtman, N. (2012). Understanding peer effects in financial decisions: Evidence from a field experiment (No. w18241). National Bureau of Economic Research.

Donnellan, M. B., Conger, K. J., McAdams, K. K., and Neppl, T. K. (2009). Personal Characteristics and Resilience to Economic Hardship and Its Consequences: Conceptual Issues and Empirical Illustrations. Journal of Personality, 77(6), 1645-1676. doi:10.1111/j.1467-6494.2009.00596.x 
Donnellan, M. B., Oswald, F. L., Baird, B. M., and Lucas, R. E. (2006). The Mini-IPIP Scales: Tiny-yeteffective measures of the Big Five Factors of Personality. Psychological Assessment, 18(2), 192-203. doi:10.1037/1040-3590.18.2.192

Duckworth, A. L., Weir, D., Tsukayama, E., and Kwok, D. (2012). Who does well in life? Conscientious adults excel in both objective and subjective success. Frontiers in Psychology, 3.

Eccles, D. W., Ward, P., Goldsmith, E., and Arsal, G. (2013). The Relationship between Retirement Wealth and Householders' Lifetime Personal Financial and Investing Behaviors. Journal of Consumer Affairs, 47(3), 432-464. doi:10.1111/joca.12022

Fletcher, J. M. (2013a). The Effects of Childhood ADHD on Adult Labor Market Outcomes. Health Economics, 23(2), 159-181. doi:10.1002/hec.2907

Fletcher, J. M. (2013b). The effects of personality traits on adult labor market outcomes: Evidence from siblings. Journal of Economic Behavior and Organization, 89, 122-135.

Gathergood, J. (2012). Self-control, financial literacy and consumer over-indebtedness. Journal of Economic Psychology, 33(3), 590-602.

Gillen, M., and Kim, H. (2013). Older Adults’ Receipt of Financial Help: Does Personality Matter? Journal of Family and Economic Issues, 35(2), 178-189. doi:10.1007/s10834-013-9365-0

Gul, F., and Pesendorfer, W. (2004). Self-Control and the Theory of Consumption. Econometrica, 72(1), $119-158$.

Heckman, J. J., Moon, S. H., Pinto, R., Savelyev, P. A., and Yavitz, A. (2010). The rate of return to the HighScope Perry Preschool Program. Journal of Public Economics, 94(1-2), 114-128. doi:10.1016/j.jpubeco.2009.11.001

Heckman, J. J., Savelyev, P. A., and Pinto, R. (2013). Understanding the Mechanisms Through Which an Influential Early Childhood Program Boosted Adult Outcomes. American Economic Review, 103(6), 2052-2086.

Heckman, J. J., Stixrud, J., and Urzua, S. (2006). The effects of cognitive and noncognitive abilities on labor market outcomes and social behavior. Journal of Labor Economics, 24(3), 411-482. 
Heineck, G. (2011). Does it pay to be nice? Perosnality and earnings in the United Kingdom. Industrial and Labor Relations Review, 64(5), 1020-1038. doi:10.2307/41343711?ref=no-xroute:2fb616255ec8b9196679c450cb3631a0

Hill, P. L., Turiano, N. A., Mroczek, D. K., and Roberts, B. W. (2012). Examining concurrent and longitudinal relations between personality traits and social well-being in adulthood. Social Psychological and Personality Science, 3(6), 698-705.

Jackson, J. J., Hill, P. L., Payne, B. R., Roberts, B. W., and Stine-Morrow, E. A. (2012). Can an old dog learn (and want to experience) new tricks? Cognitive training increases openness to experience in older adults. Psychology and Aging, 27(2), 286.

John, O. P., Naumann, L. P., and Soto, C. J. (2008). Paradigm shift to the integrative big five trait taxonomy. Handbook of Personality: Theory and Research, 3, 114-158.

Letkiewicz, J. C., and Fox, J. J. (2014). Conscientiousness, Financial Literacy, and Asset Accumulation of Young Adults. Journal of Consumer Affairs, 48(2), 274-300.

Lundberg, S. (2013). The College Type: Personality and Educational Inequality. Journal of Labor Economics, 31(3), 421-441. doi:10.1086/671056

McAdams, D. P., and Pals, J. L. (2006). A new Big Five: fundamental principles for an integrative science of personality. American Psychologist, 61(3), 204

Moffitt, T.E., Arseneault, L., Belsky, D., Dickson, N., Hancox, R.J., Harrington, H.L., Houts, R., Poulton, R., Roberts, B.W., Ross, S., Sears, M.R., Thomson, W.M., and Caspi, A. (2011) A gradient of childhood self-control predicts health, wealth, and public safety. Proceedings from the National Academy of Sciences, 108, 2693-2698.

Nyhus, E. K., and Webley, P. (2001). The role of personality in household saving and borrowing behaviour. European Journal of Social Psychology, 15(S1), S85-S103. doi:10.1002/per.422

Rapee, R. M., Kennedy, S., Ingram, M., Edwards, S., and Sweeney, L. (2005). Prevention and early intervention of anxiety disorders in inhibited preschool children. Journal of Consulting and Clinical Psychology, 73(3), 488. 
Roberts, B. W. (2006). Personality development and organizational behavior. In B. M. Staw, (pp. 1-40). Research in Organizational Behavior — An Annual Series of Analytical Essays and Critical Reviews.

Roberts, B. W. (2009). Back to the future: Personality and Assessment and personality development. Journal of Research in Personality, 43(2), 137-145.

Roberts, B. W., Jackson, J. J., Duckworth, A. L., and Culin, Von, K. (2011). Personality Measurement and Assessment in Large Panel Surveys. Health, 14(3), 9.

Roberts, B. W., Kuncel, N. R., Shiner, R., Caspi, A., and Goldberg, L. R. (2007). The power of personality: The comparative validity of personality traits, socioeconomic status, and cognitive ability for predicting important life outcomes. Perspectives on Psychological Science, 2(4), 313-345.

Roberts, B. W., Lejuez, C., Krueger, R. F., Richards, J. M., and Hill, P. L. (2014). What is conscientiousness and how can it be assessed? Developmental Psychology, 50(5), 1315.

Slade, A., and Beller, A. H. (2013). The Role of Family Structure in the Evolution of Health from Adolescence to Young Adulthood by Gender. Unpublished Manuscript, Department of ACE, UIUC.

Thaler, R. H., and Shefrin, H. M. (1981). An economic theory of self-control. Journal of Political Economy, 89(2), 392-406.

Trautwein, U., Lüdtke, O., Roberts, B. W., Schnyder, I., and Niggli, A. (2009). Different forces, same consequence: conscientiousness and competence beliefs are independent predictors of academic effort and achievement. Journal of Personality and Social Psychology, 97(6), 1115-1128.

Uysal, S. D., and Pohlmeier, W. (2011). Unemployment duration and personality. Journal of Economic Psychology, 32(6), 980-992. doi:10.1016/j.joep.2011.03.008

VandenBos, G. R. E. (2007). APA Dictionary of Psychology. (G. R. VandenBos). American Psychological Association.

Viinikainen, J., and Kokko, K. (2012). Personality traits and unemployment: Evidence from longitudinal data. Journal of Economic Psychology, 33(6), 1204-1222. doi:10.1016/j.joep.2012.09.001 
Yao, R., and Xu, Y. (2015). Chinese Urban Households’ Security Market Participation: Does Investment Knowledge and Having a Long-term Plan Help? Forthcoming in Journal of Family and Economic Issues 
Table 1. Descriptive Statistics

\begin{tabular}{|c|c|c|}
\hline & (1) & (2) \\
\hline VARIABLES & $\mathrm{M}$ & SD \\
\hline \multicolumn{3}{|l|}{ Dependent Variables } \\
\hline past 12 months no utility payment & .150 & .357 \\
\hline past 12 months no phone service & .088 & .283 \\
\hline past 12 months no mortgage/rent payment & .096 & .294 \\
\hline insolvent if liquidate all asset & .194 & .395 \\
\hline past year worried food depleted & .115 & .319 \\
\hline welfare/public assistant & .244 & .430 \\
\hline Composite measure of financial distress & .886 & 1.309 \\
\hline \multicolumn{3}{|l|}{ Personality Traits } \\
\hline Conscientiousness & 14.569 & 2.703 \\
\hline Neuroticism & 10.384 & 2.741 \\
\hline Extraversion & 13.227 & 3.079 \\
\hline Agreeableness & 15.195 & 2.451 \\
\hline Openness & 14.452 & 2.471 \\
\hline \multicolumn{3}{|l|}{ Background } \\
\hline biomother and biofather & .546 & .498 \\
\hline biomother only & .194 & .395 \\
\hline biomother and stepfather/socialfather & .136 & .343 \\
\hline no biomother & .124 & .329 \\
\hline health==excellent/very good & .673 & .469 \\
\hline health==good & .256 & .437 \\
\hline health==fair/poor & .070 & .256 \\
\hline depression-w1 & .096 & .295 \\
\hline ADHD ever-w4 & .058 & .233 \\
\hline parent: less than high school & .146 & .353 \\
\hline parent: high school graduate & .519 & .500 \\
\hline parent: college graduate & .274 & .446 \\
\hline parent: missing education & .061 & .240 \\
\hline math: A & .248 & .432 \\
\hline math: B & .293 & .455 \\
\hline math: below B & .378 & .485 \\
\hline math: not taken & .075 & .264 \\
\hline math: not in ABCD & .005 & .073 \\
\hline \multicolumn{3}{|l|}{ Demographic Controls } \\
\hline female & .495 & .500 \\
\hline white & .658 & .474 \\
\hline black & .159 & .366 \\
\hline Hispanic & .118 & .322 \\
\hline Asian & .035 & .184 \\
\hline other race & .030 & .172 \\
\hline age at Wave IV & 28.375 & 1.698 \\
\hline Census Northeast Region & .124 & .330 \\
\hline Census Midwest Region & .287 & .452 \\
\hline Census South Region & .415 & .493 \\
\hline Census West Region & .174 & .379 \\
\hline local unemployment rate & .081 & .080 \\
\hline ever married by Wave IV & .505 & .500 \\
\hline less than high school & .089 & .284 \\
\hline
\end{tabular}


high school graduate

.603

.489

college graduate

.308

.462

HH Income-w4

HH income: $<\$ 29,999$

.207

.405

HH income:\$30,000-\$49,999

.211

.408

HH income:\$50,000-\$74,999

.228

.420

HH income:\$75,000-\$99,999

.143

.350

HH income: $>\$ 100,000$

.210

.407

Observations

13470

Note: Summary statistics are weighted by Wave IV cross-sectional sampling weight. 


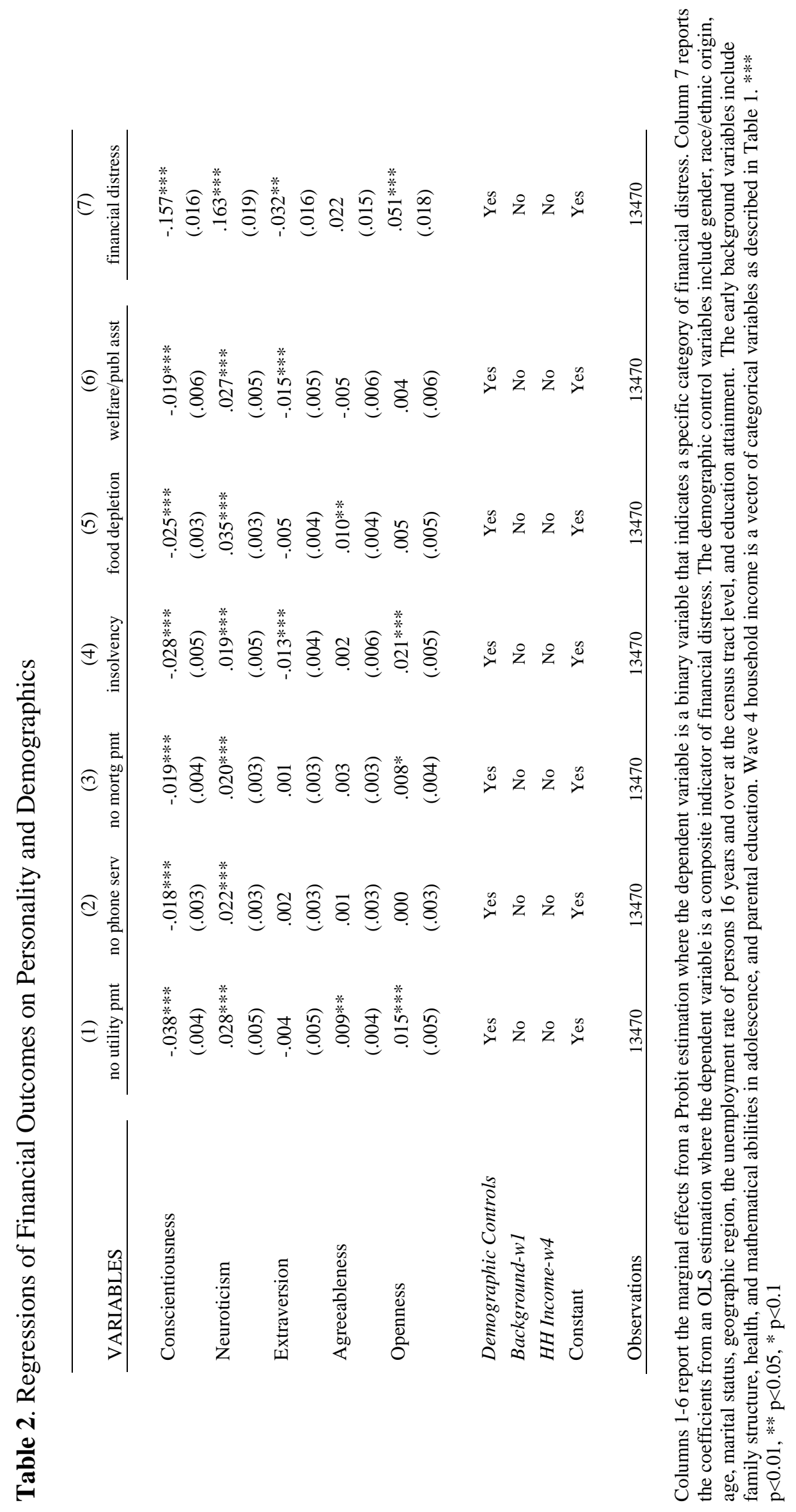




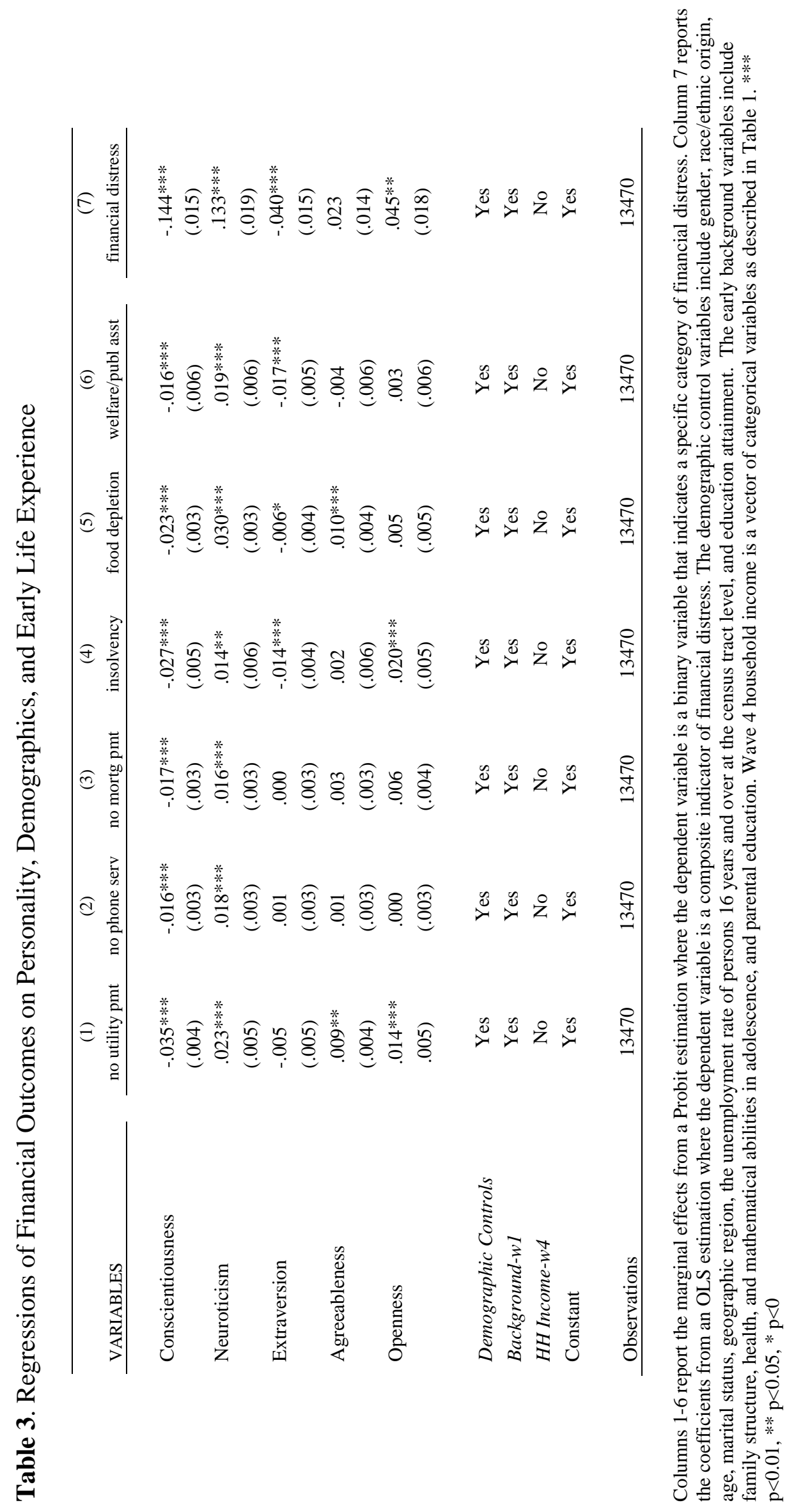




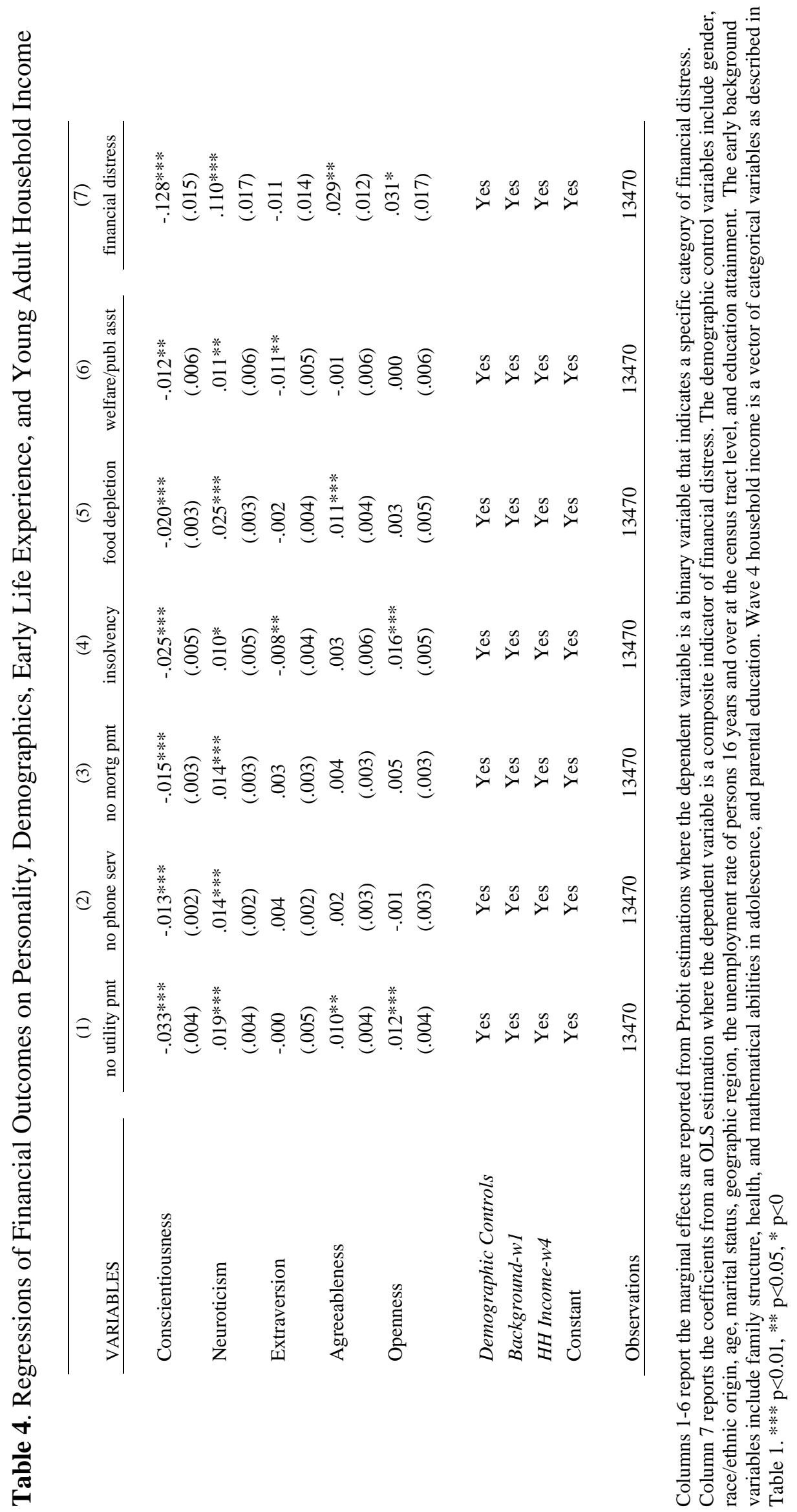




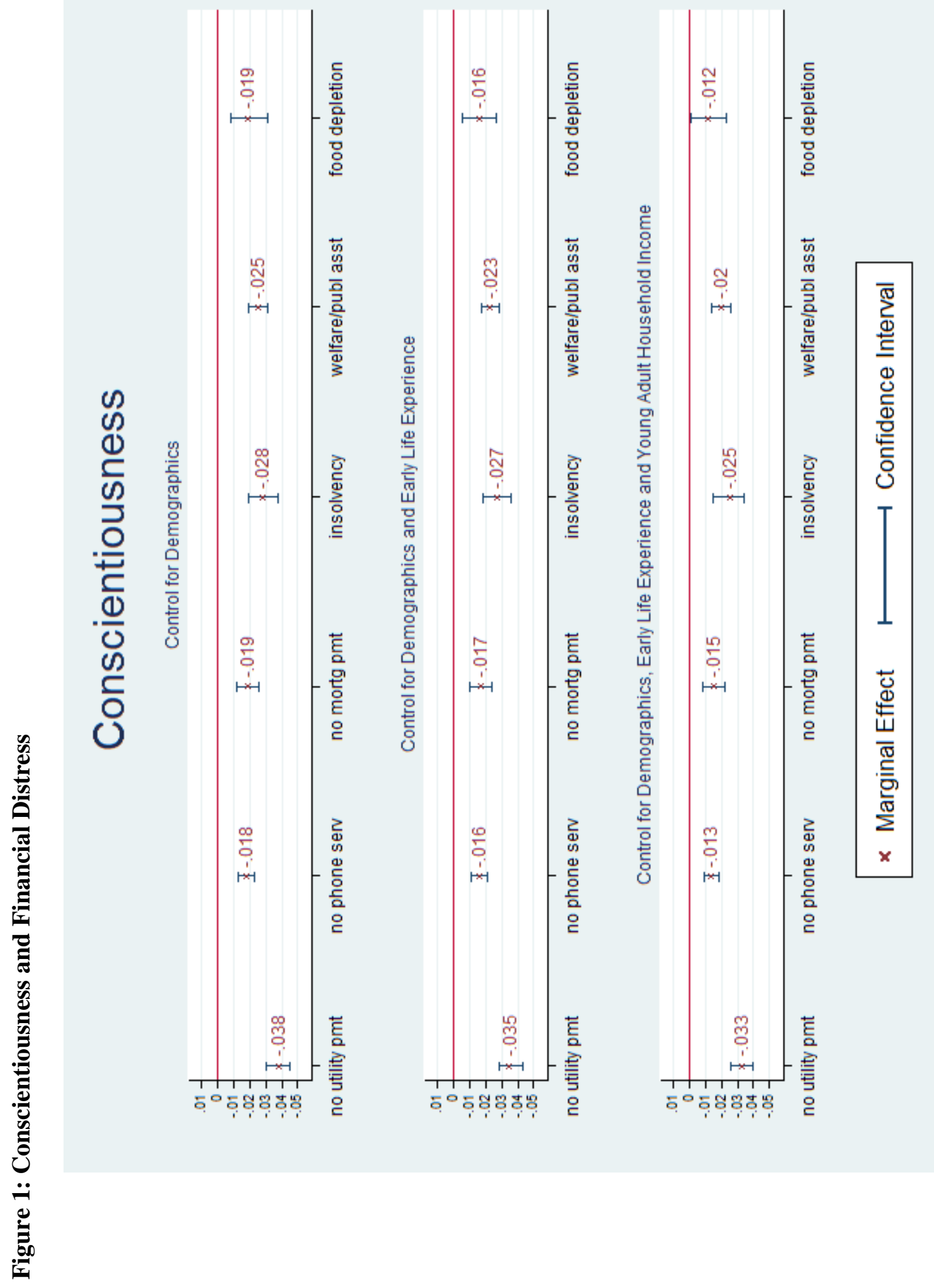

하 


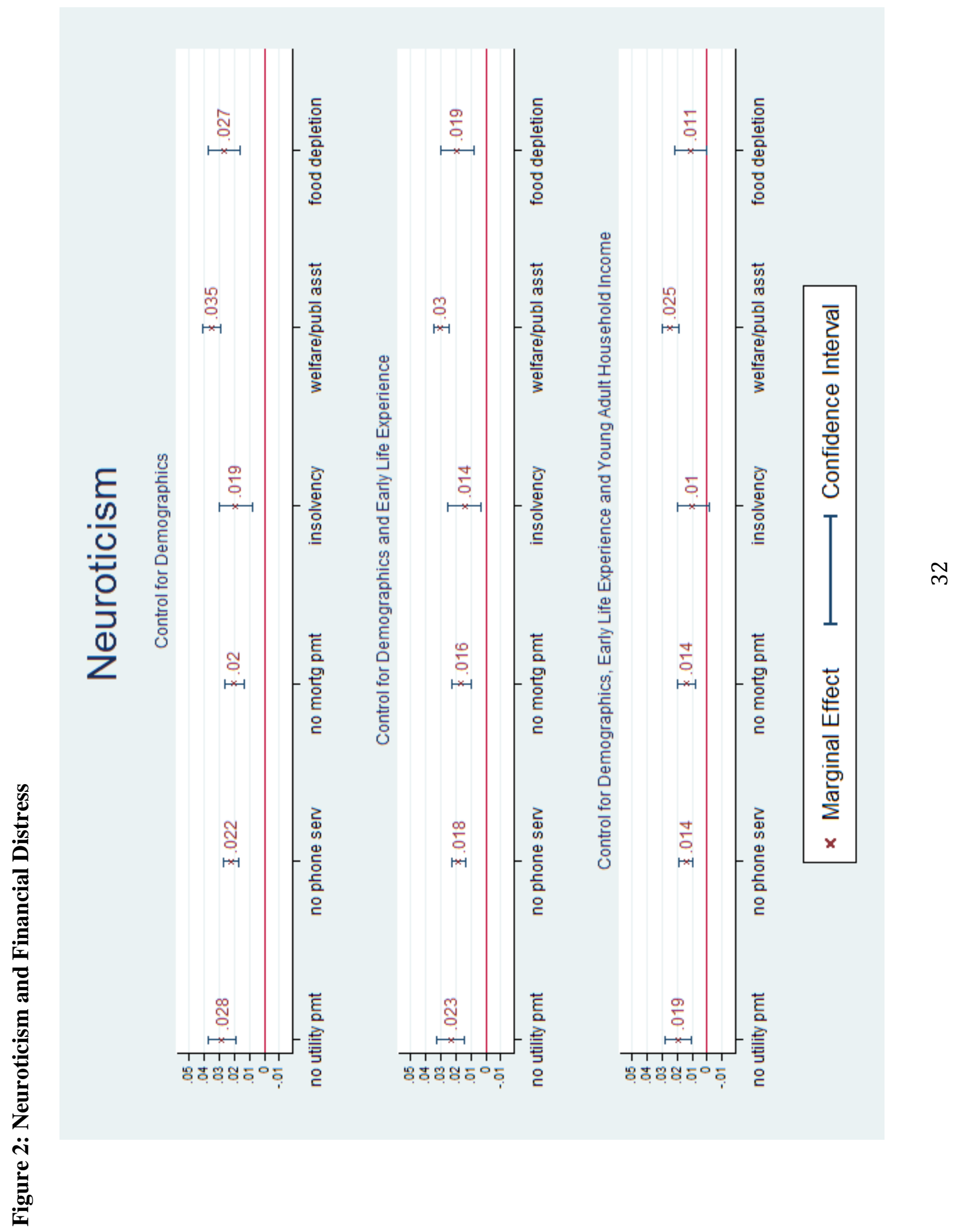

